Rubiyanti, N. · Y. Rochayat

\title{
Pengaruh konsentrasi paklobutrazol dan waktu aplikasi terhadap mawar batik (Rosa hybrida L.)
}

\section{Effect of paclobutrazol concentration and time of aplication to batik rose}

Diterima : Januari 2015/Disetujui : Februari 2015/Dipublikasikan : Maret 2015

CDepartment of Crop Science, Padjadjaran University

\begin{abstract}
Rosesare popular ornamental plants and has a high economic value, one of which is a rose has pattern like batik in corolla. This research was conducted determine the effect concenteration and time aplication paclobutrazol to growth and flowering Batik rose (Rosa hybrida L.). This research was conducted at the field nursery in Cihideung, Lembang West Java Province which is located at the altitude 800 meters above sea levels in the month of April to June 2014. The experimental design were used Randomized Design Group with ten treatment and three replication. The treatments were consisted of: without paclobutrazol (control); paclobutrazol $250 \mathrm{ppm}+4$ weeks after budding; paclobutrazol $250 \mathrm{ppm}+6$ weeks after budding; paclobutrazol $250 \mathrm{ppm}+8$ weeks after budding; paclobutrazol 500 ppm + 4 weeks after budding; paclobutrazol $500 \mathrm{ppm}+6$ weeks after budding; paclobutrazol $500 \mathrm{ppm}+8$ weeks after budding; paclobutrazol $750 \mathrm{ppm}+4$ weeks after budding; paclobutrazol $750 \mathrm{ppm}+6$ weeks after budding; paclobutrazol $750 \mathrm{ppm}+8$ weeks after budding. The results showed that the aplication of paclobutrazol significantly affect reduction in height, number of leaf, stem diameter, number of branches, chlorophyll content, turn up primordia, height flower bud, and flower diameter. Treatment with consentration 250 ppm with time aplication 4 week after grafting gave the best result for meet the criteria of a potted roses.
\end{abstract}

Keywords : Batic rose - Paclobutrazol . Aplication time

\begin{tabular}{l}
\hline Dikomunikasikan oleh Erni Suminar \\
\hline Rubiyanti, N. $^{2}$. Y. Rochayat \\
1 Staf Pengajar Program Studi Agroteknologi Fakultas \\
Pertanian Universitas Padjadjaran \\
${ }^{2}$ Alumni Fakultas Pertanian Universitas Padjadjaran \\
Korespondensi: dryayat_effendi@yahoo.com
\end{tabular}

Sari Mawar merupakan tanaman hias yang populer dan memiliki nilai ekonomi yang tinggi, salah satunya adalah mawar batik yang memiliki motif seperti batik pada mahkotanya. Percobaan ini dilakukan untuk mengetahui pengaruh konsentrasi dan waktu aplikasi paklobutrazol terhadap pertumbuhan dan pembungaan mawar batik (Rosa hybridaL.). Percobaan ini dilaksanakan di Kebun Pembi-bitan Mawar, Desa Cihideung, Lembang Jawa Barat yang berada pada ketinggian tempat 800 meter di atas permukaan laut pada bulan April sampai Juni 2014. Rancangan Percobaan yang digunakan adalah Rancangan Acak Kelompok (RAK) terdiri dari sepuluh perlakuan dengan tiga ulangan. Perlakuan terdiri dari; tanpa pemberian paklobutrazol (kontrol); paklobutrazol 250 ppm +4 minggu setelah okulasi; paklobutrazol 250 ppm +6 minggu setelah okulasi; paklobutrazol 250 ppm +8 minggu setelah okulasi; paklobutrazol $500 \mathrm{ppm}+4$ minggu setelah okulasi; paklobutrazol $500 \mathrm{ppm}+6 \mathrm{MSO}$; paklobutrazol $500 \mathrm{ppm}+8$ minggu setelah okulasi; paklobutrazol $750 \mathrm{ppm}+4$ minggu setelah okulasi; paklobutrazol $750 \mathrm{ppm}+6$ minggu setelah okulasi; paklobutrazol $750 \mathrm{ppm}$ + 8 minggu setelah okulasi. Hasil penelitian menunjukkan bahwa pemberian konsen-trasi dan waktu aplikasi paklobutrazol berpengaruh terhadap pertambahan tinggi, jumlah daun, diameter batang, jumlah cabang, klorofil daun, waktu muncul primordia bunga, tinggi tunas bunga, diameter bunga, dan jumlah bunga per tanaman. Perlakuan dengan konsentrasi 250 ppm yang diaplikasikan pada 4 minggu setelah okulasi memberikan hasil terbaik pada pertumbuhan dan pembungaan mawar batik.

Kata kunci : Mawar batik · Paklobutrazol . Waktu aplikasi 


\section{Pendahuluan}

Mawar merupakan salah satu tanaman hias yang cukup populer dan banyak digemari di kalangan masyarakat karena bunganya yang cantik, warnanya indah dan terkadang mengeluarkan bau yang harum ketika dicium. Tanaman mawar hingga saat ini masih menjadi primadona diantara bunga-bunga lainnya setelah anggrek dan krisan, maka tidak mengherankan apabila mawar termasuk komoditas utama tanaman hias yang bernilai ekspor tinggi dan terus meningkat permintaannya baik di dalam maupun di luar negeri (Rukmana, 1995).

Beragamnya kegunaan dari bunga ini seperti digunakan sebagai penghias taman, tanaman pot, dekorasi pada acara-acara besar atau bahkan diberikan sebagai tanda kasih kepada seseorang, hal ini membuktikan bahwa mawar selain memiliki nilai ekonomi dan sosial yang cukup tinggi, bunga jenis ini juga memiliki prospek yang cerah untuk dikembangkan menjadi komoditas perdagangan dan komersil.

Berdasarkan data Badan Pusat Statistik pada tahun 2012 menunjukkan produksi bunga mawar dari tahun 2009-2012 selalu mengalami fluktuasi. Pada tahun 2009 produksi mawar potong di Jawa Barat mencapai 4.471.566 tangkai kemudian mengalami kenaikan pada tahun 2010 menjadi 12.233.896 tangkai. Akan tetapi pada tahun 2011 produksi mawar potong mengalami penurunan menjadi 7.770 .033 tangkai dan pada tahun 2012 kembali meningkat menjadi 13.959.736 tangkai. Tidak hanya permintaan pada mawar potong yang selalu mengalami fluktuasi produksi, begitu juga dengan mawar pot yang dimanfaatkan sebagai tanaman di dalam ruangan (in door plant) juga mengalami hal yang sama.Terjadinya fluktuasi produksi pada mawar salah satunya dapat disebabkan oleh lemahnya produsen dalam menjaga kestabilan produksinya sehingga peningkatan permintaan konsumen terhadap mawar tidak dapat diimbangi dengan peningkatan produksi.

Menurut Arifin (2009) mawar batik merupakan persilangan antara mawar lokal dengan mawar impor yang hasilnya dapat dilihat dari kuntum mawar yang bermotif. Motif yang ditimbulkan berasal dari persilangan warna mawar yang berbeda seperti misalnya persilangan mawar merah tua dengan mawar putih menghasilkan kuntum bunga bermotif merah putih. Lama kesegaran mawar batik dapat bertahan hingga 15 hari.
Mawar sebagai tanaman hias pot umum-nya lebih mengutamakan ukuran tanamanyang tidak terlalu tinggi sehingga bisa disimpan di dalam ruangan maupun di luar ruangan. Mawar batik tidak hanya mengutamakan keindahan dari bunganya yang bermotif tetapi juga dari bentuk tanamannya seperti bentuk yang kompak, batang yang kokoh, daun yang lebat serta munculnya bunga yang seragam dan kontinyu akan memberikan nilai tambah pada tanaman. Salah satu faktor yang dapat menyebabkan bentuk tanaman mawar memiliki kriteria tersebut adalah dengan pemberian paklobutrazol. Pemberian paklobutrazol pada tanaman Consolida orientalis memberikan penampilan yang berbeda terhadap warna daun menjadi lebih hijau, warna bunga yang lebih tajam dan pertumbuhan menjadi kompak (Mansuroglu, et al 2009).

Menurut Wattimena (1989), tanaman tidak akan menunjukkan respon terhadap zat pengatur tumbuh yang bersangkutan apabila tidak diberikan pada masa pekanya. Masa peka dapat meliputi waktu pemberian paklobutrazol pada pagi atau sore hari ataupun waktu pemberian yang disesuaikan dengan kondisi tanaman yang sedang tumbuh pada fase vegetatif atau reproduktif.Waktu yang tepat saat pemberian paklobutrazol akan efektif menghambat pembentukkan kerja giberellin atau merangsang kerusakan giberellin sehingga konsentrasi giberellin dalam tanaman menurun. Terhambatnya biosintesis giberellin karena pemberian paklobutrazol menyebabkan laju pembelahan dan pemanjangan sel menjadi Iambat tanpa menyebabkan keracunan pada sel. Pengaruh langsung paklobutrazol pada morfologi tanaman adalah pengurangan pertumbuhan vegetatif (Rosita dkk., 1996).

Mawar batik yang termasuk ke dalam tipe standar mampu mencapai ketinggian tanaman hingga 1-1,5 m sehingga bentuknya menjadi kurang proporsional apabila dimanfaatkan sebagai tanaman hias pot, maka dari itu pemberian paklobutrazol pada tanaman mawar batik perlu dilakukan sebagai upaya penghambatan terhadap pertumbuhan vegetatif dan merangsang pembungaan pada tanaman mawar batik.

\section{Bahan dan Metode}

Percobaan dilaksanakan di kebun pembibitan di Desa Cihideung Kabupaten Bandung Barat, pada ketinggian tempat $800 \mathrm{~m} \mathrm{dpl}$, suhu harian sekitar 
17-24 ${ }^{\circ} \mathrm{C}$ dan curah hujan $2500 \mathrm{~mm} / \mathrm{th}$. Waktu penelitian dilaksanakan dari bulan April hingga bulan Juni 2014. Bahan tanaman yaitu bibit mawar batik yang berumur 4 minggu setelah okulasi (MSO), 6 minggu setelah okulasi dan umur 8 minggu setelah okulasi, ditanam dalam polybag ukuran 18 x $18 \mathrm{~cm}$ dengan menggunakan media tanam berupa sekam : pupuk kandang sapi dan perbandingan (8:1). Rancangan percobaan yang digunakan yaitu Rancangan Acak Kelompok yang terdiri dari sepuluh perlakuan terdiri dari A (Tanpa pemberian paklobutrazol); B (Paklobutrazol 250 ppm aplikasi 4 minggu setelah okulasi); C (Paklobutrazol 250 ppm aplikasi 6 minggu setelah okulasi); D (Paklobutrazol 250 ppm aplikasi 8 minggu setelah okulasi); E (Paklobutrazol 500 ppm aplikasi 4 minggu setelah okulasi), F (Paklobutrazol 500 ppm aplikasi 6 minggu setelah okulasi); G (Paklobutrazol 500 ppm aplikasi 8 minggu setelah okulasi); $\mathrm{H}$ (Paklobutrazol 750 ppm aplikasi 4 minggu setelah okulasi); I (Paklobutrazol 750 ppm aplikasi 6 minggu setelah okulasi); J (Paklobutrazol 750 ppm aplikasi 8 minggu setelah okulasi). Setiap perlakuan diulang sebanyak tiga kali. Paklobutrazol diberikan satu kali dengan cara disiramkan pada media sesuai konsentrasi masing-masing dengan volume $100 \mathrm{~mL} /$ polybag (Suradinata dkk., 2011). Pupuk NPK, insektisida dan fungisida diberikan satu minggu sekali. Data dianalisis dengan menggunakan analisis ragam dan bila terdapat pengaruh nyata dilanjutkan dengan Uji Scott Knot taraf 5\%.

\section{Hasil dan Pembahasan}

Pertambahan Tinggi Tanaman. Hasil analisis statistik menunjukkan kombinasi pemberian paklobutrazol dan waktu aplikasi yang berbeda, mempengaruhi pertumbuhan tinggi tanaman pada 8 dan 12 minggu setelah aplikasi paklobutrazol.

Pada Tabel 1. tanaman yang diberi paklobutrazol memiliki pertambahan tinggi rata-rata yang lebih rendah dibandingkan tanaman kontrol, ini merupakan pengaruh yang ditimbulkan dari paklobutrazol yang meng-hambat produksi giberellin. Runtunuwu dkk. (2011) menyatakan tinggi tanaman merupakan hasil dari pembelahan dan pemanjangan sel-sel meristem apikal yang distimulasi oleh zat pengatur tumbuh (growth regulator) giberellin, sehingga kekurangan giberellin akan mengakibatkan pertumbuhan yang kerdil pada tanaman. Hal ini sesuai dengan penelitian Runtunuwu dkk. (2011) yang menunjukkan paklobutrazol dapat mempengaruhi pertumbuhan bibit cengkeh menjadi lebih pendek seiring dengan semakin tingginya konsentrasi paklobutrazol yang diberikan. Begitu pula pada tanaman anggrek pemberian paklobutrazol mampu mengambat pertumbuhan tinggi tunas anggrek (Rachmi dkk., 2012).

Tabel 1. Pengaruh Paklobutrazol dan Waktu Aplikasi terhadap Pertambahan Tinggi Tanaman Mawar Batik.

\begin{tabular}{cccc}
\hline \hline \multirow{2}{*}{ Perlakuan } & \multicolumn{3}{c}{$\begin{array}{c}\text { Rata-rata pertambahan tinggi } \\
\text { tanaman }(\mathbf{c m}) \text { pada umur }\end{array}$} \\
\cline { 2 - 4 } & 4 MSA & $\mathbf{8}$ MSA & 12 MSA \\
\hline $\mathrm{A}$ & $8,66 \mathrm{a}$ & $10,63 \mathrm{a}$ & $21,13 \mathrm{a}$ \\
$\mathrm{B}$ & $4,81 \mathrm{a}$ & $0,55 \mathrm{~b}$ & $0,88 \mathrm{~b}$ \\
$\mathrm{C}$ & $4,08 \mathrm{a}$ & $0,42 \mathrm{~b}$ & $0,70 \mathrm{~b}$ \\
$\mathrm{D}$ & $3,08 \mathrm{a}$ & $0,30 \mathrm{~b}$ & $1,21 \mathrm{~b}$ \\
$\mathrm{E}$ & $4,32 \mathrm{a}$ & $0,42 \mathrm{~b}$ & $0,88 \mathrm{~b}$ \\
$\mathrm{~F}$ & $5,16 \mathrm{a}$ & $0,22 \mathrm{~b}$ & $0,30 \mathrm{~b}$ \\
$\mathrm{G}$ & $4,22 \mathrm{a}$ & $0,30 \mathrm{~b}$ & $0,63 \mathrm{~b}$ \\
$\mathrm{H}$ & $4,77 \mathrm{a}$ & $0,40 \mathrm{~b}$ & $0,68 \mathrm{~b}$ \\
$\mathrm{I}$ & $4,07 \mathrm{a}$ & $0,33 \mathrm{~b}$ & $0,43 \mathrm{~b}$ \\
$\mathrm{~J}$ & $5,47 \mathrm{a}$ & $0,27 \mathrm{~b}$ & $0,32 \mathrm{~b}$ \\
\hline \hline
\end{tabular}

Keterangan : Nilai rata-rata perlakuan yang ditandai dengan huruf yang sama pada kolom yang sama menunjukkan tidak berbeda nyata berdasarkan Uji Scott-Knott pada taraf nyata $5 \%$.

MSA = minggu setelah aplikasi

Paklobutrazol merupakan bahan penghambat pertumbuhan yang bekerja pada bagian sub meristem dengan cara menghambat biosintesis giberelin dalam tanaman melalui penghambatan terhadap oksidasi kauren menjadi asam kauren sehingga terjadi penghambatan terhadap perpanjangan dan pembesaran sel (Mahgoub et al ., 2006). Giberellin merupakan salah satu hormonyang terdapat dalam tanaman berbentuk senyawa isoprena yang berperan dalam pemanjangan dan pembesaran sel juga merangsang pembungaan (Lakitan, 1996).

Volume dan Panjang Akar. Tabel 2. menunjukkan konsentrasi paklobutrazol dan waktu aplikasi tidak memberikan pengaruh yang berbeda nyata pada semua perlakuan terhadap volume akar dan panjang akar. Tidak adanya perbedaan yang nyata pada volume maupun panjang akar, menunjukkan tidak terjadi pengaruh paklobutrazol terhadap akar. 
Tabel 2. Pengaruh Paklobutrazol dan Waktu Aplikasi terhadap Volume Akar dan Panjang Akar.

\begin{tabular}{ccc}
\hline \hline \multirow{2}{*}{ Perlakuan } & \multicolumn{2}{c}{$\begin{array}{c}\text { Rata-rata Volume Akar dan } \\
\text { Panjang Akar }\end{array}$} \\
\cline { 2 - 3 } & $\begin{array}{c}\text { Volume Akar } \\
(\mathbf{m L})\end{array}$ & $\begin{array}{c}\text { Panjang Akar } \\
(\mathbf{c m})\end{array}$ \\
\hline $\mathrm{A}$ & $31,67 \mathrm{a}$ & $29,33 \mathrm{a}$ \\
$\mathrm{B}$ & $30,00 \mathrm{a}$ & $33,33 \mathrm{a}$ \\
$\mathrm{C}$ & $25,00 \mathrm{a}$ & $29,00 \mathrm{a}$ \\
$\mathrm{D}$ & $21,67 \mathrm{a}$ & $34,80 \mathrm{a}$ \\
$\mathrm{E}$ & $11,67 \mathrm{a}$ & $30,70 \mathrm{a}$ \\
$\mathrm{F}$ & $20,00 \mathrm{a}$ & $29,90 \mathrm{a}$ \\
G & $18,33 \mathrm{a}$ & $32,37 \mathrm{a}$ \\
$\mathrm{H}$ & $16,67 \mathrm{a}$ & $26,97 \mathrm{a}$ \\
I & $18,33 \mathrm{a}$ & $33,03 \mathrm{a}$ \\
J & $25,00 \mathrm{a}$ & $31,30 \mathrm{a}$ \\
\hline \hline
\end{tabular}

Keterangan : Nilai rata-rata perlakuan yang ditandai dengan huruf yang sama pada kolom yang sama menunjukkan tidak berbeda nyata berdasarkan Uji Scott-Knott pada taraf nyata 5\%.

MSA = minggu setelah aplikasi

Translokasi fotosintesis yang terhambat juga dapat mengakibatkan kecenderungan akar menjadi lebih kecil dan jumlahnya sedikit. Pendugaan lain yang menyebabkan volume dan panjang akar tidak berbeda nyata yaitu paklobutrazol tidak memberikan penghambatan terhadap biosintesis auksin yang berfungsi menstimulasi pembentukan akar tetapi bekerja menghambat biosintesis giberellin dengan cara menghambat pembentukan kaurent menjadi asam kaurenat. Menurut Wattimena (1989), giberellin berinteraksi dengan hormon lain seperti auksin dalam mempengaruhi berbagai proses fisiologi seperti pembelahan dan pembesaran sel pada tanaman, perbedaan antara giberellin dan auksin dalam proses tersebut adalah giberellin lebih banyak mendorong pemanjangan batang utuh sedangkan auksin pada potongan-potongan organ tanaman seperti akar dan stek tunas. Menurut Latimer (1991) pemberian growth retardan memberikan sedikit pengaruh terhadap pertumbuhan akar, hal ini juga didukung oleh Kim dan Suzuki (1989) yang menyatakan bahwa penggunaan growth retardan lebih membatasi terhadap pertumbuhan batang dibandingkan pada akar.

Komponen Pembungaan. Pembungaan merupakan peristiwa yang menandakan telah terjadinya perubahan pola pertumbuhan dan perkembangan dari proses-proses vegetatif menjadi reproduktif. Tanaman akan menghasilkan bunga bila tanaman tersebut telah melewati masa vegetatif dimana terjadi pertambahan besar, berat dan menimbunnya zat cadangan makanan lebih banyak terutama karbohidrat sebagai bahan utama pembentukan bunga. Tanaman akan berbunga setelah mencapai tingkat kematangan tertentu (Moningka dkk., 2012). Tabel 3 menunjukkan bahwa kombinasi paklobutrazol dan waktu aplikasi memberikan pengaruh yang berbeda nyata terhadap panjang tangkai bunga, diameter bunga dan jumlah bunga per tanaman.

Pemberian paklobutrazol pada waktu yang lebih cepat akan mempengaruhi panjang tangkai bunga menjadi lebih pendek, tetapi peningkatan konsentrasi paklobutrazol tidak mempengaruhi tinggi tunas menjadi semakin pendek. Hal ini sejalan dengan pernyataan Wattimena (1989) yang menyatakan bahwa tanaman tidak akan menunjukkan respon terhadap zat pengatur tumbuh yang bersangkutan apabila tidak diberikan pada masa pekanya begitu juga diperkuat oleh penyataan Davis, (1991) bahwa aplikasi paklobutrazol yang terlambat diberikan pada waktu pertumbuhan kemungkinan efek dari paklobutrazol tidak terlihat secara nyata hingga pertumbuhan selanjutnya.

Tabel 3. Pengaruh Paklobutrazol dan Waktu Aplikasi terhadap Komponen Pembungaan.

\begin{tabular}{cccc}
\hline \hline & \multicolumn{3}{c}{ Komponen Pembungaan } \\
\cline { 2 - 4 } Perlakuan & $\begin{array}{c}\text { Panjang } \\
\text { Tangkai } \\
\text { Bunga } \\
\mathbf{( c m )}\end{array}$ & $\begin{array}{c}\text { Diameter } \\
\text { Bunga } \\
\left.\mathbf{( c m}^{2}\right)\end{array}$ & $\begin{array}{c}\text { Jumlah } \\
\text { Bunga }\end{array}$ \\
\hline $\mathrm{A}$ & $9,36 \mathrm{a}$ & $6,78 \mathrm{a}$ & $118 \mathrm{a}$ \\
$\mathrm{B}$ & $2,22 \mathrm{c}$ & $4,93 \mathrm{c}$ & $1,15 \mathrm{a}$ \\
$\mathrm{C}$ & $5,97 \mathrm{~b}$ & $5,49 \mathrm{~b}$ & $1,04 \mathrm{~b}$ \\
$\mathrm{D}$ & $9,17 \mathrm{a}$ & $6,83 \mathrm{a}$ & $1,00 \mathrm{~b}$ \\
$\mathrm{E}$ & $2,66 \mathrm{c}$ & $4,25 \mathrm{~d}$ & $1,22 \mathrm{a}$ \\
$\mathrm{F}$ & $3,16 \mathrm{c}$ & $4,96 \mathrm{c}$ & $1,00 \mathrm{~b}$ \\
$\mathrm{G}$ & $9,80 \mathrm{a}$ & $6,71 \mathrm{a}$ & $1,00 \mathrm{~b}$ \\
$\mathrm{H}$ & $2,34 \mathrm{c}$ & $0,00 \mathrm{e}$ & $1,07 \mathrm{~b}$ \\
$\mathrm{I}$ & $5,37 \mathrm{~b}$ & $4,74 \mathrm{c}$ & $1,00 \mathrm{~b}$ \\
$\mathrm{~J}$ & $9,43 \mathrm{a}$ & $6,48 \mathrm{a}$ & $1,00 \mathrm{~b}$ \\
\hline \hline
\end{tabular}

Keterangan : Nilai rata-rata perlakuan yang ditandai dengan huruf yang sama pada kolom yang sama menunjukkan tidak berbeda nyata berdasarkan Uji Scott-Knot pada taraf nyata 5\%.

MSA = minggu setelah aplikasi

Diameter bunga yang dihasilkan oleh semua perlakuan yang berhasil berbunga secara sempurna berkisar 4,25-6,83 cm sedangkan pada perlakuan $\mathrm{H}$ (paklobutrazol 750 ppm + 4 MSO) tidak menghasilkan bunga yang berhasil mekar secara sempurna hal ini disebabkan konsentrasi 
yang diberikan diduga terlalu tinggi untuk tanaman mawar batik yang berumur 4 minggu setelah okulasi (MSO) menyebabkan bunga mengering dan mati sebelum mekar. Perlakuan E (paklobutrazol $500 \mathrm{ppm}+4 \mathrm{MSO})$, menghasilkan diameter bunga paling kecil yaitu 4,25 $\mathrm{cm}$. Pemberian konsentrasi paklobutrazol dan waktu aplikasi menghasilkan diameter bunga yang beragam, hal ini menunjukkan bahwa penghambatan oleh paklobutrazol terhadap giberellin cukup efektif dalam penghambatan diameter bunga dibandingkan kontrol. Pada beberapa hasil penelitian paklobutrazol terhadap tanaman menyebabkan perbedaan diameter bunga yang dihasilkan. Qrunfleh dan Suwwan, (1988) dalam penelitiannya menyatakan pemberian paklobutrazol memberikan pengaruh terhadap diameter

Bunga Pasiflora grandiflora tetapi tidak mempengaruhi diameter pada Cosolida chinensis dan Consolida officinalis. Respon diameter bunga terhadap paklobutrazol pada tanaman cukup beragam bergantung pada jenis dan kultivar tanaman (Mansuroglu dkk., 2009).

Gambar 1. Kondisi Mawar Kontrol (Tanpa Paklobutrazol) (A) dan Mawar yang Diberi Perlakuan 250 ppm Paklobutrazol (B).

Pemberian konsentrasi paklobutrazol dan waktu aplikasi berpengaruh nyata terhadap jumlah bunga per tanaman pada mawar batik. Rata-rata jumlah bunga per tanaman (Gambar 1) pada semua perlakuan memiliki jumlah bunga berkisar antara 1.00 - 1.22 bunga per tanaman. Hasil penelitian Karaguzel (2004) menunjukkan konsentrasi pemberian paklobutrazol (2.500 $\mathrm{mg}$ /tanaman) yang tinggi pada Lupinus varius menghasilkan jumlah bunga yang lebih sedikit dibandingkan kontrol begitu juga halnya pemberian paklobutrazol pada Gladiolus tristis mempengaruhi jumlah bunga yang dihasilkan dalam satu tanaman, jumlah bunga pada bunga ini menjadi lebih sedikit dengan meningkatnya konsentrasi yang diberikan.

\section{Kesimpulan dan Saran}

\section{Kesimpulan}

1. Konsentrasi dan waktu aplikasi paklobutrazol mempengaruhi pertambahan tinggi, panjang tangkai bunga, diameter bunga dan jumlah bunga per tanaman.

2. Konsentrasi paklobutrazol dan waktu aplikasi yang terbaik adalah 250 ppm diaplikasikan 4 minggu setelah okulasi pada tanaman mawar batik.

Saran

Perlu dilakukan percobaan pemberian paklobutrazol pada konsentrasi yang lebih rendah dari 250 ppm dengan cara disiram pada umur mawar batik 4 minggu setelah okulasi.

\section{Ucapan Terima Kasih}

Ucapan terima kasih saya berikan kepada Ibu Anne Nuraini dan semua pihak yang terlibat.

\section{Daftar Pustaka}

Badan Pusat Statistik. 2012. Luas Panen Produksi dan Produktivitas Tanaman Hias Menurut Provinsi Tahun 2009-2012. Badan Pusat Statistik. Jakarta. (www.bps.go.id). Diakses 28 Desember 2013.

Davis, Tim.D. 1991. Regulation of tree growth and development with triazole compunds. Journal of Arboculture 17(16):167-169.

Karaguzel, O., I. Baktir., S. Cakmakci. dan V. Ortacesme. 2004. Growth and flowering responses of Lupinus varius $L$. to paclobutrazol. HortScience 39(7): 1659-1663.

Kim, H.Y., Abe, T., Watanabe, H. And Suzuki, Y. 1989. Changes in flower bud development of zinnia elegans as influenced by growth retardant s-07. J. Hort. Sci., 64(1):81-89.

Lakitan, Benyamin .1996. Fisiologi Pertumbuhan dan Perkembangan Tanaman. Raja Grafindo Persada: Jakarta 
Latimer, J.G. 1991. Growth retardants affect landscape of Zinnia, Impatiens and Marigold. Hortscience, 26(5):557-560.

Mahgoub, M H., N. G. Abd El Aziz and A. A. Youssef. 2006. Influence of foliar spray with paklobutrazol or glutathione on growth, flowering and chemical composition of calendula officinalis L. Plant. J. App Sci Res. 2 (11): 879 - 883

Mansuroglu, S., O. Karaguzel, V. Ortacesme and M.S. Sayan. 2009. Effect of Paclobutrazol on Flowering Leaf and Colour of Consolida orientalis. Pak. J. Bot., 41(5): 2323-2332.

Moningka, F. F., S. D, Runtunuwu.dan J.M. Paulus. 2012. Respon pertumbuhan tinggi dan produksi tanaman cengkeh (Syzigium aromaticum $L$ ) terhadap pemberian paklobutrazol. Eugenia, 18(2):118-127.

Qrunfleh, M.M dan M.A. Suwwan. 1988. Response of three summer annuals to paclobutrazol application. Advance in Horticultural Science, 2(1): 15-18.

Rachmi H. Hasan., Sarawa., dan I Gusti R. Sadimantara. 2012. Respon tanaman ang-grek
Dendrobium sp. terhadap pemberian paklobutrazol dan pupuk organik cair. Jurnal Agronomi, 1(1):73-78.

Rukmana R. 1995. Mawar. Yogyakarta: Kanisius. Rosita, S. D. M., Ireng Darwati., dan Sri Yuliani. 1996. Pengaruh Paklobutrazol terhadap Pertumbuhan dan Produksi Kencur. Bogor: Balittro

Runtunuwu, S. D. 2011. Konsentrasi Paclo-butrazol dan Pertumbuhan Tinggi Bibit Cengkeh (Syzygium aromaticum (L) Merryl \& Perry). Euginia, 17(2):135-141.

Suradinata,Y.S., Ramadhani R., dan Jajang Sauman H. 2011. Paclobutrazol Application and Shading Levels Effect to the Growth and Quality of Begonia (Begonia rex-cultorum) Cultivar Marmaduke. Asian J. of Agric. and Rural Dev., 3(8): 566-575.

Wattimena, G. A. 1989. Zat Pengatur Tumbuh . Zainul Arifin. 2009. Mawar Candy Bisa Bertahan Sampai 15 Hari. Surabaya Post. Malang Raya. Available at (http://malangraya.web.id/ 2009/09/01/mawar-candy-bisabertahansampai15-hari/) Diakses 30 Desember 2013. 